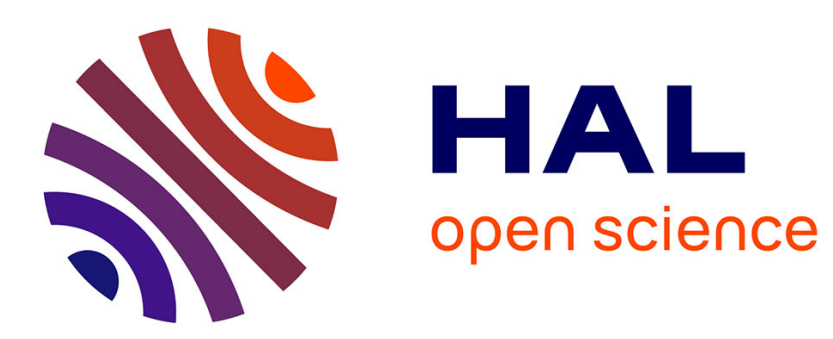

\title{
Cellular solids studied by x-ray tomography and finite element modeling - a review
}

Clémence Petit, Sylvain Meille, Éric Maire

\section{To cite this version:}

Clémence Petit, Sylvain Meille, Éric Maire. Cellular solids studied by x-ray tomography and finite element modeling - a review. Journal of Materials Research, 2013, 28 (17), pp.2191-2201. 10.1557/jmr.2013.97 . hal-02475378

\section{HAL Id: hal-02475378 https://hal.science/hal-02475378}

Submitted on 28 Jan 2021

HAL is a multi-disciplinary open access archive for the deposit and dissemination of scientific research documents, whether they are published or not. The documents may come from teaching and research institutions in France or abroad, or from public or private research centers.
L'archive ouverte pluridisciplinaire HAL, est destinée au dépôt et à la diffusion de documents scientifiques de niveau recherche, publiés ou non, émanant des établissements d'enseignement et de recherche français ou étrangers, des laboratoires publics ou privés. 


\section{Cellular solids studied by X-ray tomography and finite element modelling - a review}

Clémence Petit, Sylvain Meille, Eric Maire

INSA de Lyon, MATEIS CNRS UMR5510

Université de Lyon

69621 VILLEURBANNE, FRANCE

Corresponding author: eric.maire@insa-lyon.fr

Keywords: X-Ray Tomography, Cellular solids, Finite Element

\section{Introduction}

Cellular solids can be defined as materials with a volume fraction of porosity higher than $70 \%$. They have been known in their natural form for a very long time (trabecular bone, wood, cork, sponges, wools...). The structure of these highly porous solids is characterized by the presence of porous cells, hence their name, surrounded by a network of solid-phase. These cells can be open or closed and their dimensions can span over several orders of magnitude, from nanometers to centimeters. The specific properties of natural cellular solids are such that they are used for a very long time in special applications where these properties are required (lightweight beams and structural parts, insulators, filters, absorbers...). Their microstructure has widely inspired engineers to produce highly porous engineering solids such as wool (glass or rock wool e.g.,) and foam (metal, polymer and ceramic foams). Over the last 20 years, interest in these materials has grown. They have numerous interesting properties qualifying them as multifunctional materials ${ }^{1,2}$. Thanks to their low relative density and good mechanical proper- ties, they can be used as lightweight sandwich cores. Their high fracture strain, together with their damaging behavior when compressed, induces a large energy absorption capacity for packaging applications and shock absorbers. Their low thermal and acoustic conductivity is interesting for heat and sound insulation. The tailored high volume fraction of open porosity favors their use as filters and bone substitutes.

However, the highly porous nature of cellular solids induces experimental difficulties in terms of 2D characterization. Different morphological parameters, such as density distribution and cell and pore size, are difficult to measure because of sample preparation problems. Nondestructive 3D images can help us to overcome this difficulty, explaining why X-ray computed tomography (XRCT) has recently become a widely used technique to study cellular materials. X-ray tomography aims at obtaining 3D images of the samples. The technique being nondestructive, it is also possible to follow the microstructure of cellular materials during in situ mechanical tests, which in turn gives us information on deformation, damage and fracture behavior. Different in situ mechanical tests have been developed so far $^{3}$ : compression, tension, fatigue, hydrostatic pressure, double torsion... The availability of 3D images of cellular materials also allows the numerical calculation of their mechanical properties through finite element (FE) modeling. Specific approaches have been developed in the last 20 years to calculate the average elastic modulus and stress concen- trations during loading of cellular 
materials. Combined with in situ testing, a comparison of experimental and modeled behavior is now possible.

This review will present the most recent articles dealing with cellular solids studied by x-ray tomography and FE modeling.

\section{X-ray tomography applied to cellular solids}

\section{A) Principle of XRCT}

The principle of XRCT has been described in many reviews. ${ }^{4,5}$ It is derived from X-ray radiography where an X-ray beam is sent through a sample and the attenuation through the sample is measured by an appropriate detector. In XRCT, this sample rotates along an axis and a radiograph is taken for different angular positions of the sample. Reconstruction software uses all of these radiographs to recalculate a $3 \mathrm{D}$ image from all the $2 \mathrm{D}$ projections. As postprocessing, it is possible by using image analysis software to visualize slices of the sample or a 3D image. A standard laboratory tomograph allows the acquisi- tion of good quality images with a minimum resolution of tomography based on a synchrotron source are also available. These are more powerful and allow a better resolution.

Tomography is able to provide 3D images of all types of cellular solids. The following sections present different examples of cellular solids observed by XRCT, reproduced from recent publications. These examples are classified regarding the nature of their solid phase. 


\section{B) Examples for cellular polymers}

Polymeric foams were the first developed cellular solids. Their large energy absorption capacity enables us to use them for packaging or for protection against shock (such as helmets). This explains the large number of recent studies on the compressive behavior of this type of foam: PVC, $^{6}$ polyurethane, ${ }^{7}$ and polypropylene ${ }^{8}$ (see Fig. 1 for 3D renderings of these materials). McDonald et al. ${ }^{9}$ also studied the tensile behavior of polyurethane foam during an in situ tensile test. Polymer foams are also widely used as templates to process ceramic or metal foams ${ }^{10}$ as illustrated in the next section.

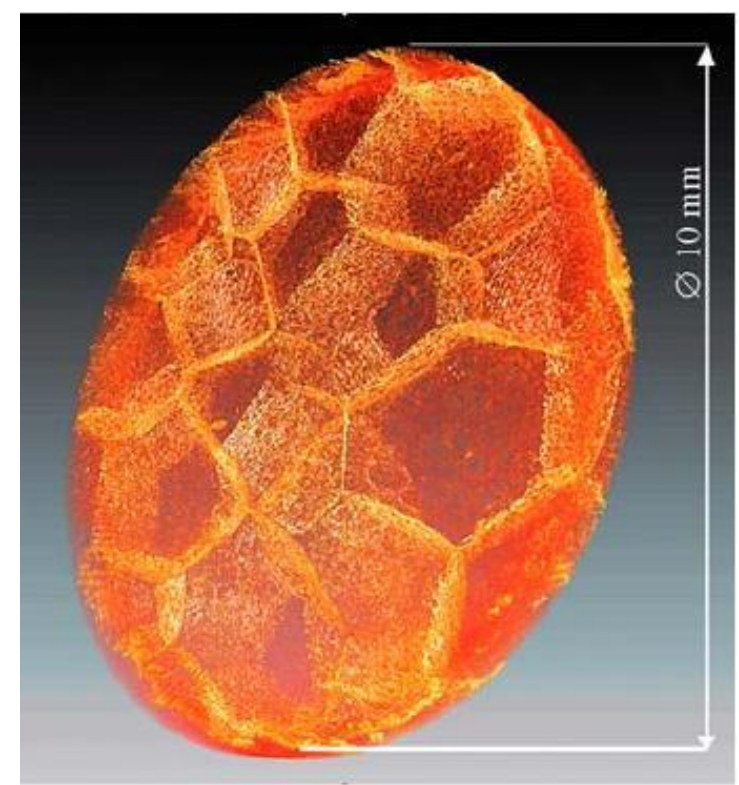

(a)

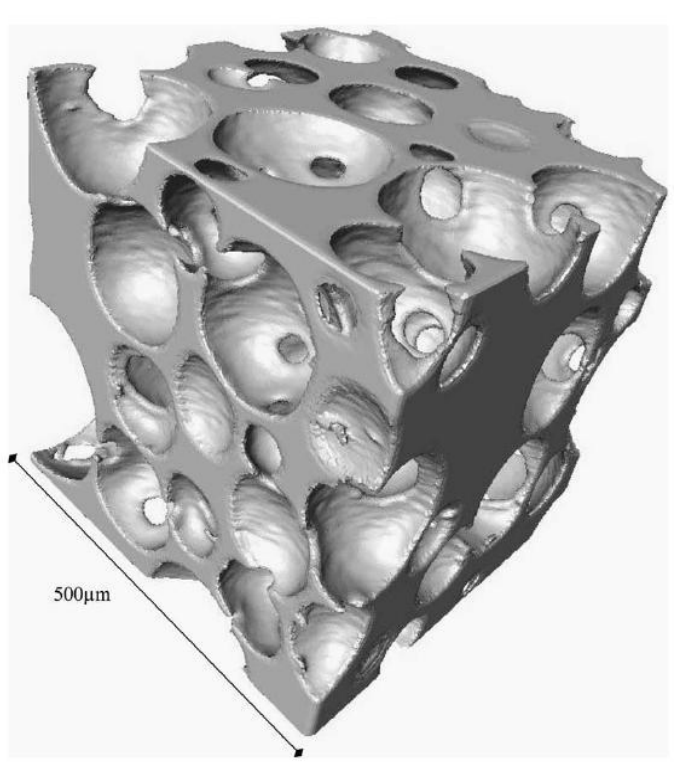

(b)

FIG. 1: X-ray tomography image of (a) a polypropylene foam ${ }^{8}$ and (b) a polyurethane foam ${ }^{7}$

\section{C) Examples for cellular ceramics}

Cellular ceramics are used in a wide range of applications: filters, solid oxide fuel cells, construction materials (cellular concrete plasterboards), biomaterials. Some authors used XRCT to characterize the morphology of the samples ${ }^{11,12}$ or their fracture processes under $\operatorname{load}^{13-15}$ (Fig. 2). Many publications deal with bone substitutes: XRCT is used to compare their mechanical properties with bones ${ }^{16}$, or to follow the interaction between bone substitutes and natural bones ${ }^{17,18}$. Figure 2(a) shows an example of a solid strut in $\mathrm{SiC}$ foam ${ }^{14}$ produced by coating a polymer cellular template with the ceramic slurry. During the sintering step at high temperature, the polymer precursor subsequently burns and then disappears, leading to the observed hollow strut structure. 


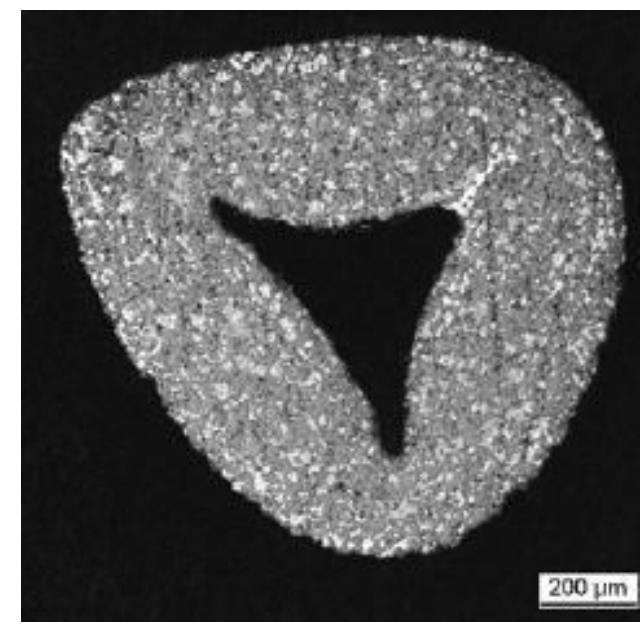

(a)

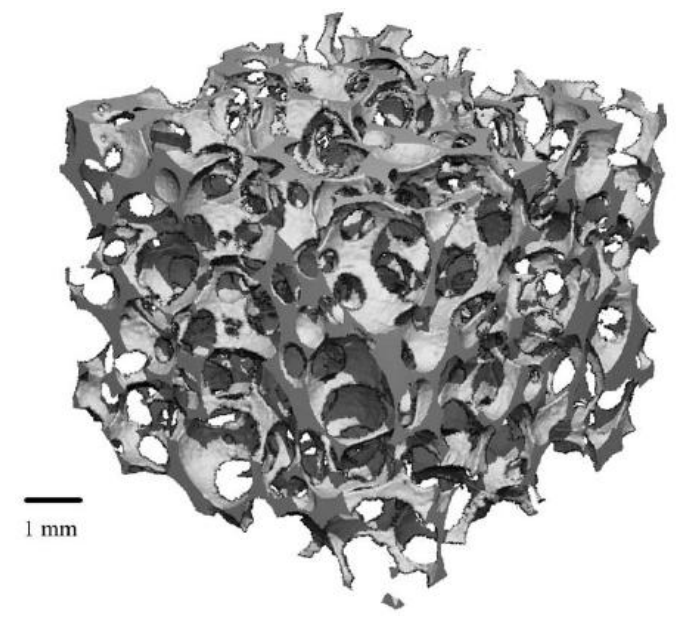

(b)

FIG. 2: XRCT images of: (a) an alumina foam ${ }^{14}$ and (b) a cross-section of a SiC foam strut ${ }^{12}$

\section{D) Examples for cellular metals}

Metal foams are a relatively recent class of cellular solids. As polymeric foams, their lightness and energy absorption capacity is extremely interesting but they can be used at higher temperatures. Moreover, cellular metals are stronger compared to cellular polymers and tougher compared to cellular ceramics. This combination of prop- erties is very interesting in load-bearing applications (sanddwich cores), or in applications that require shock absorption (automobile, helmet, packaging, and cushion). Several authors have thus investigated the mechanical behavior of aluminum alloy foams because of their set of interesting properties: low weight, high strength, ductility, corrosion resistance, and recyclability ${ }^{19-22}$. More recently, metallic materials based on other metals (copper alloy ${ }^{23}$, nickel ${ }^{10}$, steel $^{24,25}$, and titanium ${ }^{26}$ ) have also been investigated (Fig. 3).

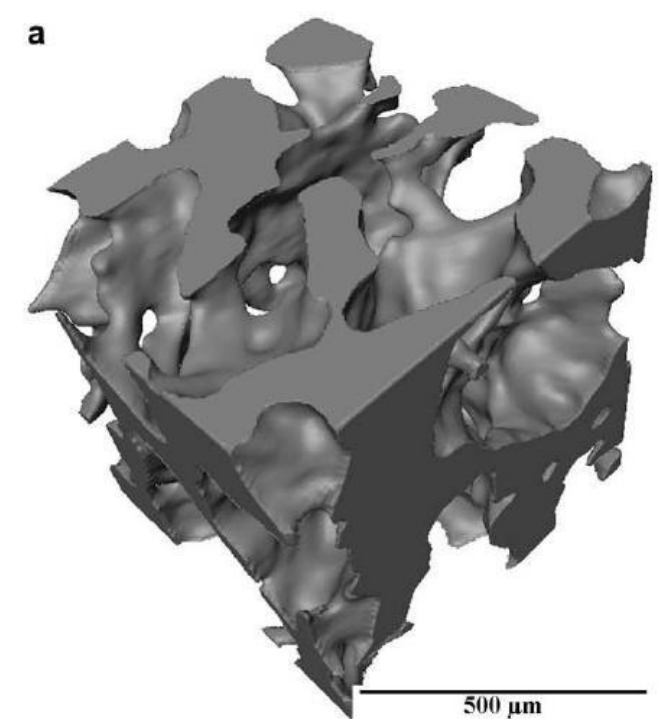

(a)

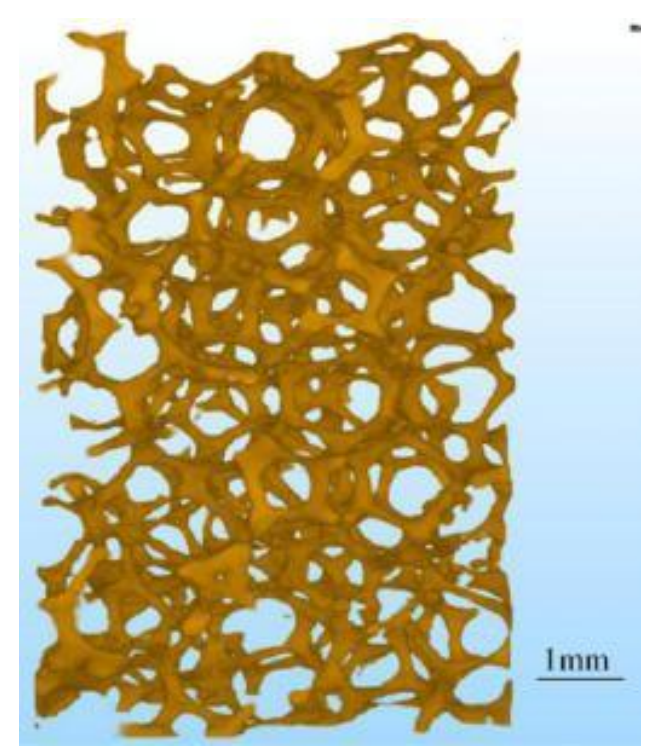

(b)

FIG. 3: (a) Ti foams ${ }^{26}$ and (b) CuSn12Ni2 foam ${ }^{23}$ 


\section{E) Image processing}

X-ray tomography is an appropriate method to observe the mesostructure of a sample, i.e., the architecture of the cell walls and the distribution between the materials and the pores. The images can also be quantitatively used to calculate important descriptors of the cellular structure: tortuosity of the different phases, density distribution, pores, and cell size distribution $^{11,27,28}$. Figure 4 shows an example of pore size distribution measured on porous metals. Tariq et al. ${ }^{29}$ determined the pore distribution in cellular ceramic catalysts thanks to tomographic images and compared it with mercury porosimetry measurements. Numerous softwares (ImageJ, IMorph ${ }^{30}$ ) have been de- veloped to improve 3D image analysis. For example, Morpho $1^{31}$ has recently been improved to enable rapid analysis of larger datasets.

One advantage of XRCT is its ability to characterize large samples, but this implies a limitation in the size resolution. To overcome this limitation, local tomography allows the imaging of the solid phase of cellular materials at a higher magnification. In this mode, the sample is placed near the x-ray source. Only a small part in the middle of the sample is irradiated by the x-rays. As a consequence, finer details of the microstructure in the material can be observed, as illustrated in Fig. 5 showing the $2 \mathrm{~mm}$ diameter central cylinder inside a $6 \mathrm{~mm}$ diameter cylindrical sample of aluminum foam $^{32}$ with microstructural details.

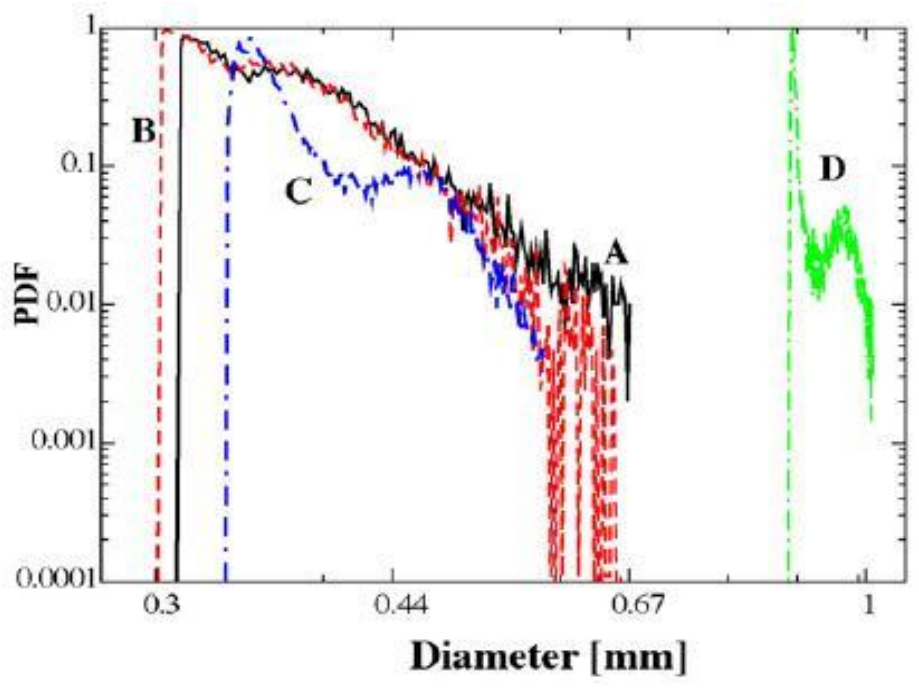

FIG. 4: Cell size distribution of four metal foams in log-normal scale (Samples A and B : AlSi7 samples, C sample : AlSi11 sample and D sample : Zn sample $)^{27}$

\section{6) In situ experiments}

Some rigs can be mounted on the rotation stage of tomographs to perform mechanical tests during scanning. The aim is to scan the sample when it undergoes a deformation. The test can be done in situ (the rig is placed in the tomograph) or ex situ (the sample is deformed outside the tomograph and observed after loading).

The images obtained during the deformation of the samples enable us to better understand the damage mech- anisms occurring inside the material.

Figure 6 shows the results obtained in an ex situ com- pression test on a hollow sphere stainless steel structure ${ }^{24}$. The image of the deformed sample allows observing the bending of the sphere walls during compression. In Fig. $7^{9}$, the alignment of the struts of polyurethane foam along the loading direction during a tensile test can be observed. 


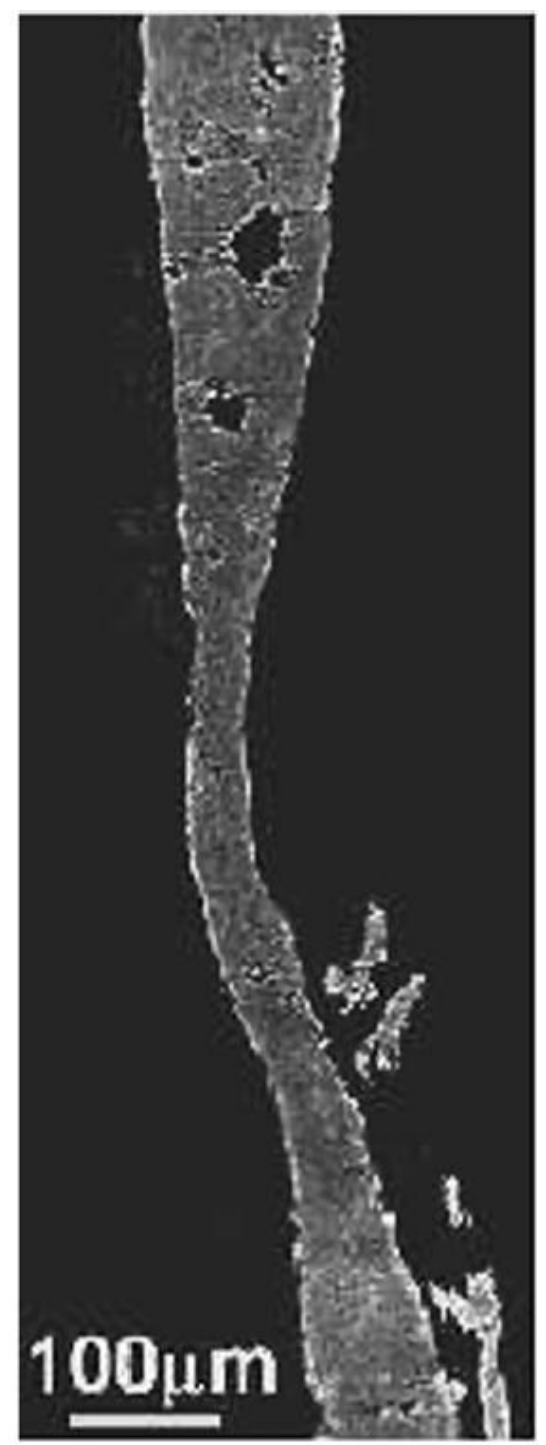

FIG. 5. Tomographic slice of a cell wall of aluminum foam imaged using the local tomography mode (the sample is larger than the detector field of view). Fine details of the microstructure as micropores ${ }^{32}$ are shown.

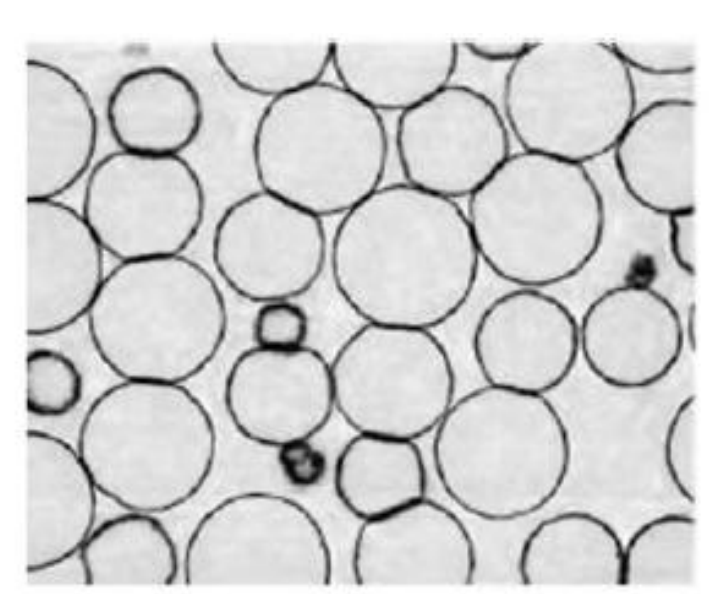

(a)

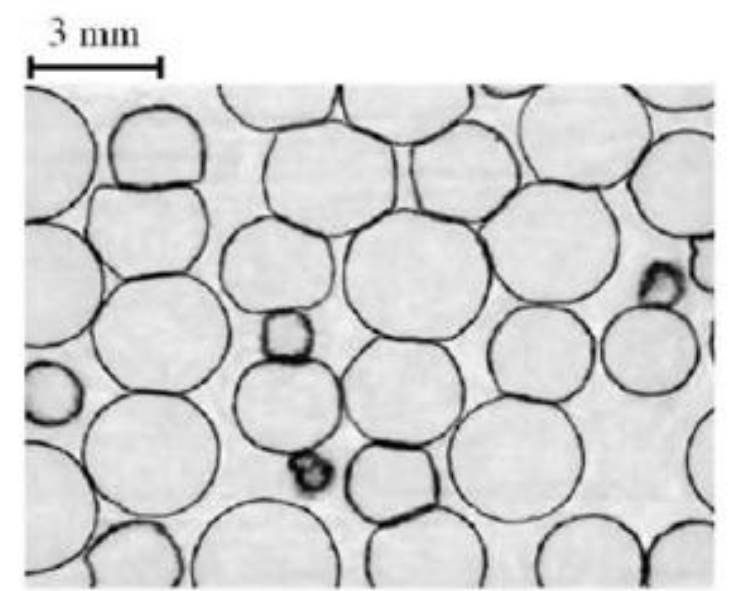

(b)

FIG. 6. Slices from tomographic images of a hollow sphere stainless steel structure: (a) Initial state and (b) after the application of a 9\% strain during a compression test ${ }^{24}$ 

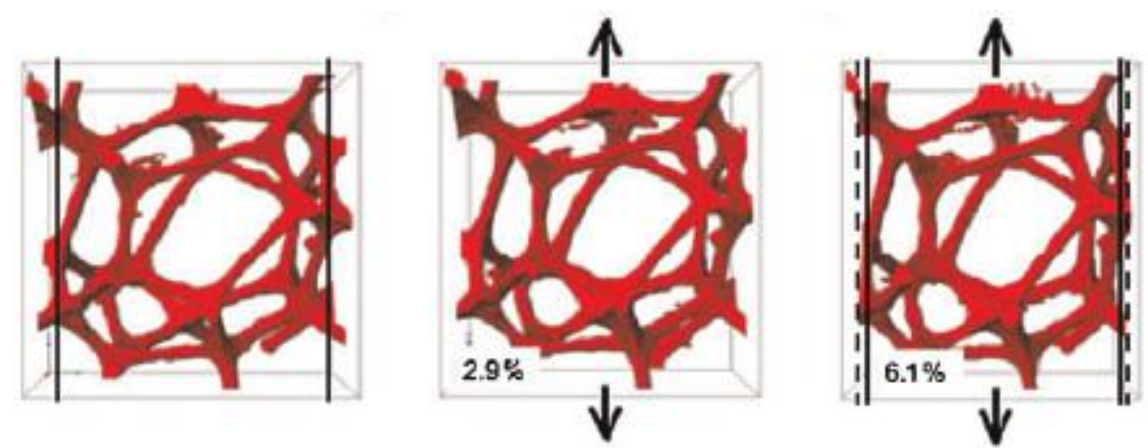

FIG. 7: Tomographic images of a PU foam during an in-situ tensile test ${ }^{9}$

\section{Finite element modelling}

Different analytical models have been developed to analyze the mechanical behavior of cellular solids, the most famous being by Gibson and Ashby ${ }^{1}$. These analytical approaches link the mechanical properties of the cellular solids to its relative density. For instance in the case of the Young's modulus, the following relation is proposed:

$$
\left(\frac{E}{E_{\mathrm{s}}}\right)=C\left(\frac{\rho}{\rho_{\mathrm{s}}}\right)^{n}
$$

where $\rho$ and $\rho_{s}$ are the density of the cellular solid and the dense constituting material, respectively, $E$ and $E_{\mathrm{s}}$ are the Young's moduli of the cellular solid and the dense constituting material, respectively. $C$ and $n$ are constants and depend on the architecture of the material, i.e., open or closed cells. Similar relationships exist for the evolution of fracture stress or fracture toughness of cellular solids versus relative density.

This relationship is based on the hypothesis that deformation in cellular materials is governed by bending. It is mostly used for periodic structures. However, the microstructure of cellular materials is usually not per- fectly periodic. This can lead to the limitation of the predictive capacity of the above models. Several approaches have been developed so far to take into account the presence of imperfections on the mechanical behavior of cellular solids ${ }^{33,34}$ using periodic structures and adding randomly dispersed imperfections. Nevertheless, such methods are not specific to a given structure and the representation simplifies the actual microstructure of cellular materials.

Numerical models and particularly FE models adapted to XRCT volumes allow the mechanical simulation of a material taking into account a realistic microstructure. Before modeling, the tomographic image has to be binarized. The binarized image is then used to create the FE mesh. The type of element selected is important to obtain an accurate model. In studies, three types of elements have been used to date:

- cubic elements,

- beams or wall elements,

- tetrahedral elements.

\section{A) Meshing with cubic elements}

This method consists of translating one voxel into an element of the mesh. The algorithm is very simple to implement and no further complex meshing steps are needed.

This meshing technique has been used on polymer, metal or ceramic cellular materials, mainly for the determination of Young's modulus and Poisson's ratio ${ }^{37-39}$, but also for the determination of the 
thermal conductivity of metal hollow sphere structures ${ }^{40}$ or the influence of the oxidation of the nuclear graphite on mechanical properties (Fig. 8) ${ }^{36}$.

The main drawback of this meshing technique is the difficulty in representing the details of the sample microstructure. The cubic elements do not correctly follow the curved surface. Different solutions exist to: increase mesh resolution (but the calculation becomes very long) as was done by Maire et $a l .{ }^{35}$ or Berre et $a l^{36}{ }^{36}$ (Fig. 8), adapt a FE program to mesh large samples ${ }^{41}$ or use the fast Fourier transform technique ${ }^{42}$. This technique is now being increasingly replaced by meshing with noncubic elements, allowing reduced computation time.

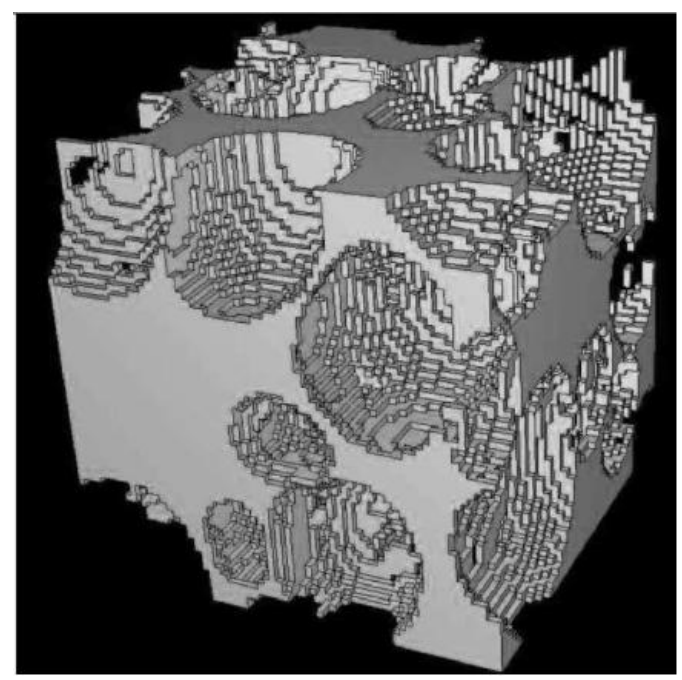

(a)

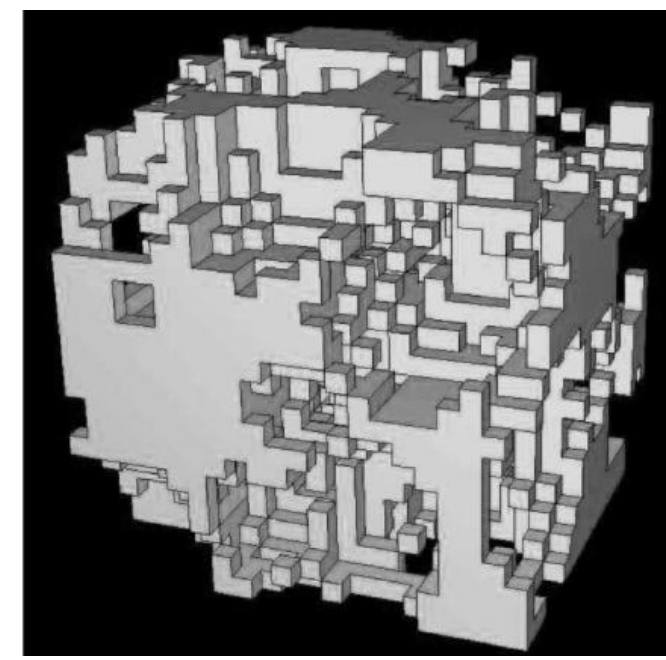

(b)

FIG 8: (a) Voxel mesh of a PU foam wih a high resolution ${ }^{35}$ and (b) Voxel mesh of the same foam with a lower resolution ${ }^{36}$

\section{b) Meshing with beams and shells}

Meshing with beam or shell elements can be used for actual structures from tomographic images provided that the microstructure is composed of such a structural element. This is, for instance, very often the case in polymer foams. Different examples exist in studies: PVC foams ${ }^{6}$ (see Fig. 9) and stainless steel hollow sphere structures ${ }^{24}$. For the latter, the structure was scanned in its initial state and this scan was used to create a FE mesh. A compression test until a strain of $9 \%$ was performed. Experimental stresses and strains were recorded during the test. The FE mesh was made with shell elements. An elastoplastic law was used to model the behavior of the solid material constituting the shells. The parameters were adjusted to take into account the pores in the steel walls: Young's modulus of $150 \mathrm{GPa}$ and Poisson ratio of 0.3 . The Young's modulus was determined using a rule of mixture with the porosity in the walls. The plastic behavior of the solid walls was modeled by couples of values for strains and stresses: [(0, $140 \mathrm{MPa}),(0.035,153.4 \mathrm{MPa}),(0.1,187 \mathrm{MPa})$, and $(0.2,210 \mathrm{MPa})]$. These values were chosen because they enable a good fit between simulation and experiments. However standard 304 steel is probably a bit harder than this. Figure 10 presents two stress strain curves: the experimental one corresponding to the com-pression test and the simulated one corresponding to the result of the FE modeling. One can observe a good correlation between experiments and modeling especially for yield stress and plastic behavior. But, the Young's modulus of the structure was overestimated. The thickness of the shell elements used was attributed based on the actual thickness of the solid-phase measured in the initial tomographic image. However, in some cases, the beam elements cannot correctly represent the structure of the material ${ }^{43}$ because the beams are not well adapted to the strut geometry 
(Fig. 11).

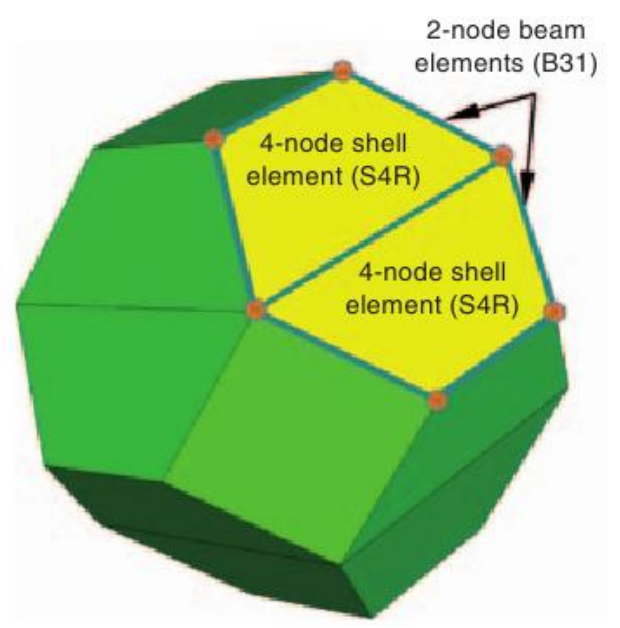

FIG. 9: Meshing of a cell of PVC foam with beam and shell ${ }^{6}$

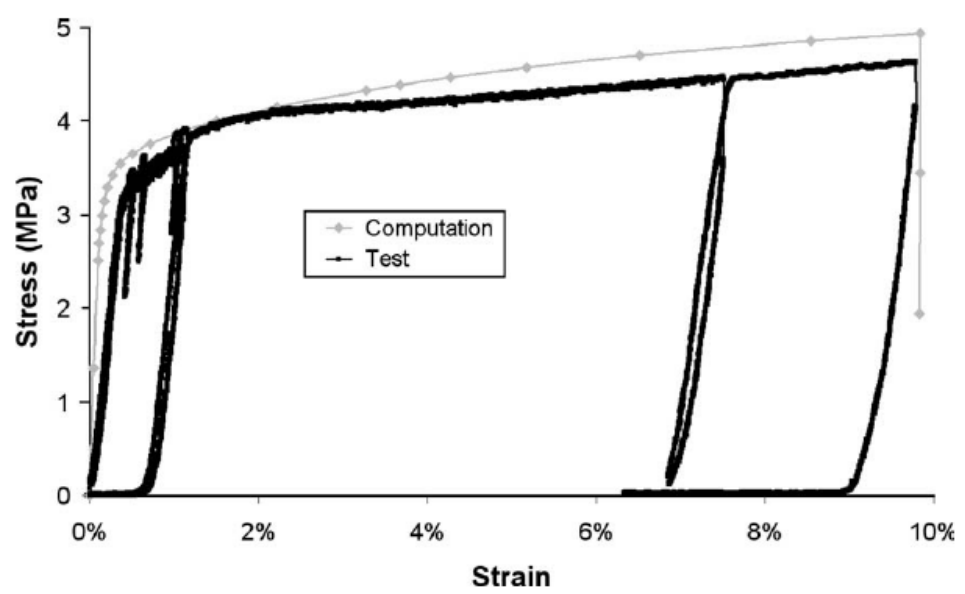

FIG. 10: Comparison between experiments and modelling for compression stress strain curve for a stainless steel hollow sphere structures ${ }^{24}$

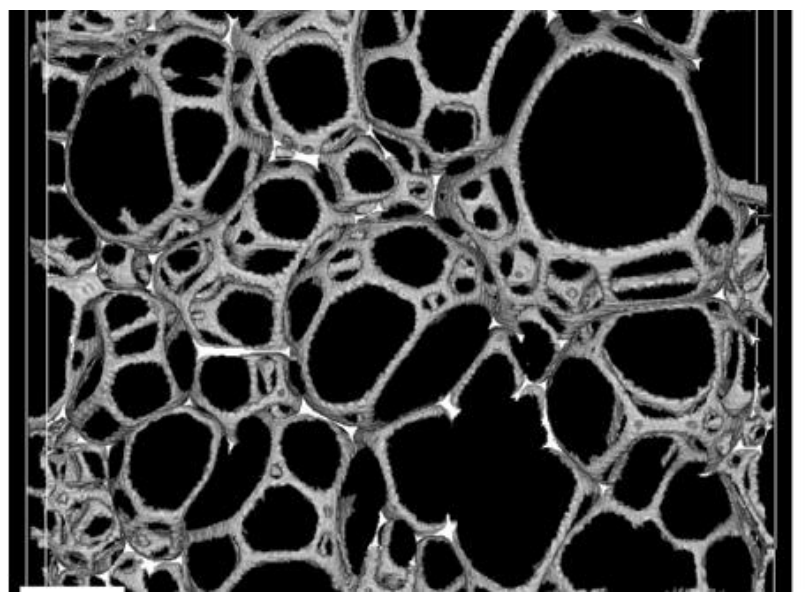

(a)

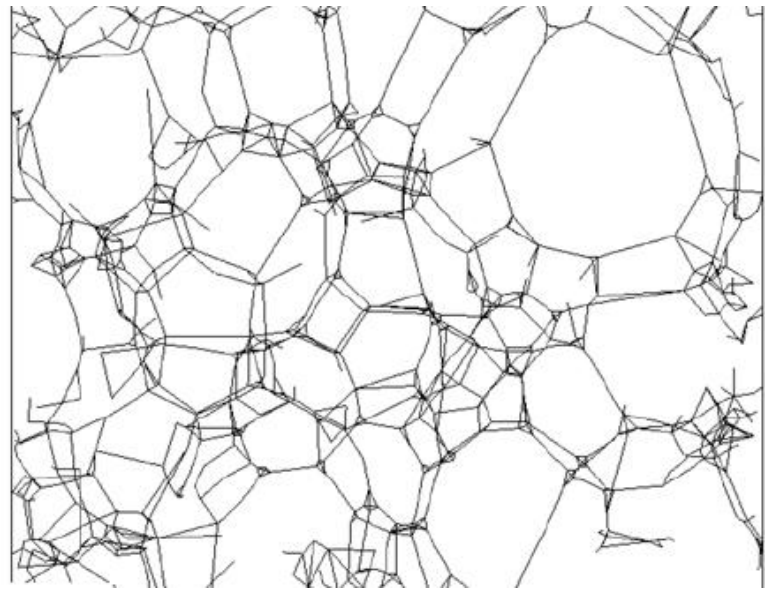

(b)

FIG. 11: (a) Tomographic image of a section of a polyurethane foam and (b) Corresponding model made with struts and nodes ${ }^{43}$ 


\section{C) Meshing with tetrahedral elements}

The third meshing technique category describes more precisely the actual structure of cellular materials. This is the most currently favored method in studies.

Meshing with tetrahedral elements is carried out in two steps. First, a 2D mesh with triangular surface elements is created from the binarized tomographic image. The triangular external faces of the elements can approximate the actual surface of the cellular solids as determined by XRCT. Then, a 3D mesh is built with a tetrahedral filling the interior of the previously defined surface. One of the first studies of tetrahedral meshing was carried out on trabecular bones $^{44}$ : a comparison was drawn between meshing with voxel and tetrahedra. For some samples, the authors obtained more accurate results with tetrahedral meshing. Examples of tetrahedral meshes created for the three types of cellular solids are presented in Fig. 12: the precise reproduction of the microstructure is particularly highlighted in Fig. 12(b). As is already presented in Fig. 10, the results obtained with tetrahedral meshes are generally close to the experimental ones (Fig. 13). A nickel foam sample was first scanned. A tensile test was performed with a displacement rate of $0.1 \mathrm{~mm} / \mathrm{min}$. The FE mesh was built from the tomographic image. An elastoplastic law was chosen to model the behavior of nickel. The parameters used in the model were: Young's modulus of $170 \mathrm{GPa}$, Poisson ratio of 0.3 and yield strength of $25 \mathrm{MPa}$. The curves presented in Fig. 13 are the experimental data from the tensile test and the simulated data created from the FE modeling. ${ }^{21}$ In this example, the Young's modulus is the same in the experiment and in the FE calculation. In terms of macroscopic properties, Vesenjak et al $^{45}$ used the method to demonstrate the influence of the anisotropy and the strain rate sensitivity on the compressive behavior of aluminum foam. It should be noticed that the use of this technique seems to overestimate the elastic stiffness (see again Fig. 10) and the authors sometimes have to use an unrealistic elastic behavior of the solid phase to fit their experimental elastic regime. For example, Marcadon et al. ${ }^{46}$ obtained overestimated Young's mod- ulus as compared to experimental ones for the compressive behavior of Inconel hollow tube stacking. No clear explanation has yet been suggested as to why the models are stiffer than the experimental materials. In terms of local behavior, the prediction is, on the contrary, always very useful to analyze the weak points in the microstructure. Figure 14 presents the simulated stress contours of a representative cell of polyurethane foam before and after a tensile test. ${ }^{9}$ The polyurethane foam was scanned in its initial state and underwent an in situ tensile test. The FE mesh was built from the tomographic image. The polyurethane behavior was considered to be elastic with Young's modulus of $45 \mathrm{MPa}$ and Poisson ratio of 0.3. The FE modeling simulates correctly the elongation of the cell in the tensile direction and the contraction in the transverse direction. The zones of stress concentrations can also be predicted (visible in brighter blue and green colors on the figure).

In cellular ceramics, as with other cellular materials, FE models of XRCT images are used to estimate the average Young's modulus and the stress concentrations within the solid phase. ${ }^{14,15,39}$ FE simulation shows stress concentration logically in the thinnest sections of the solid walls or struts. ${ }^{14}$ Some limitations are noted in these results, especially in some cases, where the estimated Young's modulus is no more accurate than the analytical solutions, such as the Gibson and Ashby model. In the study carried out by Zhang et $a .^{15}$, this finding was related to the volume size, too small in some cases to be representative of the whole microstructure of a material. As a rule of thumb, a representative volume element of a cellular material should at least encompass 10 cells across the three main directions of the solid.

Bone substitutes are an important application for cellular materials and have been the subject of recent work on property evaluation using XRCT and FE analyses. Such materials are often more dense than the cellular ceramics mentioned above, with a relative density varying from 50 to $75 \%$. The FE calculation shows in this case the important influence of the pore distribution on the stress 
distribution $^{16}$, local agglomeration of pores leading to higher stress con- centration in the solid phase.

Another issue that confirms the potential of FE simulation based on XRCT volumes is the coupling between mechanical stimuli and the biological response of cellular materials in vivo. It has been largely shown that compressive stresses enhance cell differentiation and extracellular matrix synthesis, essential factors for new bone growth. Computation of fluid flow in the porous space of a cellular matrix is also of importance ${ }^{47}$.

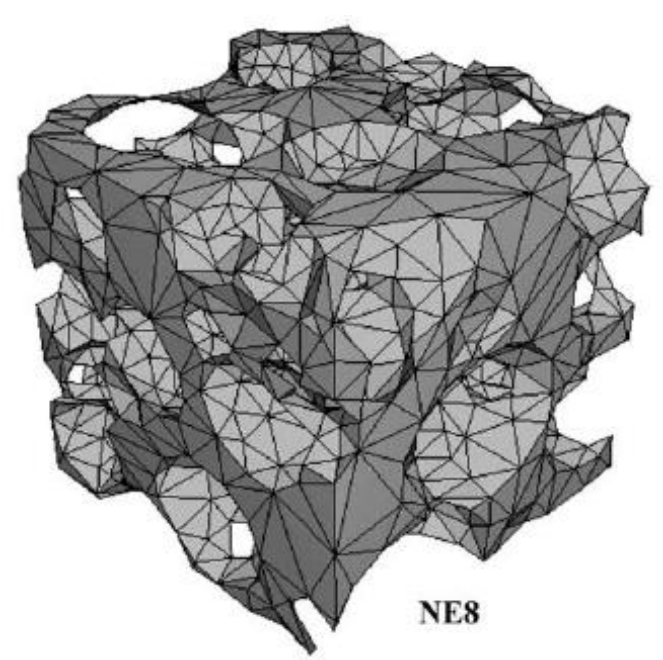

(a)

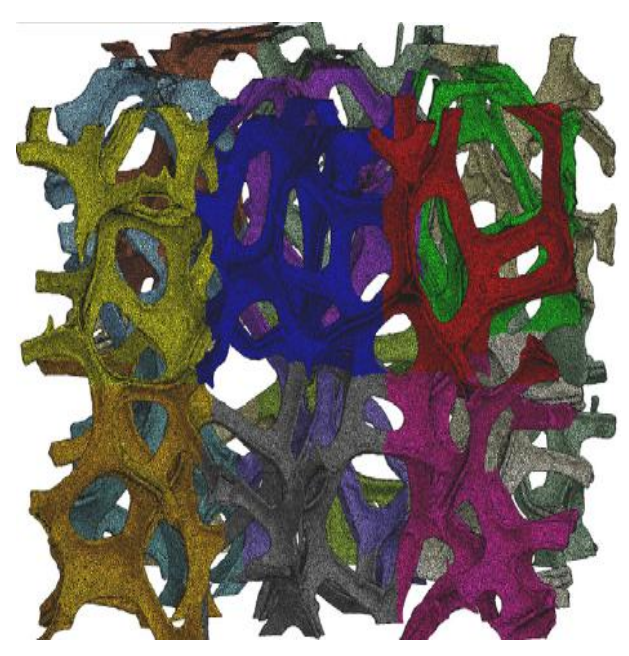

(b)

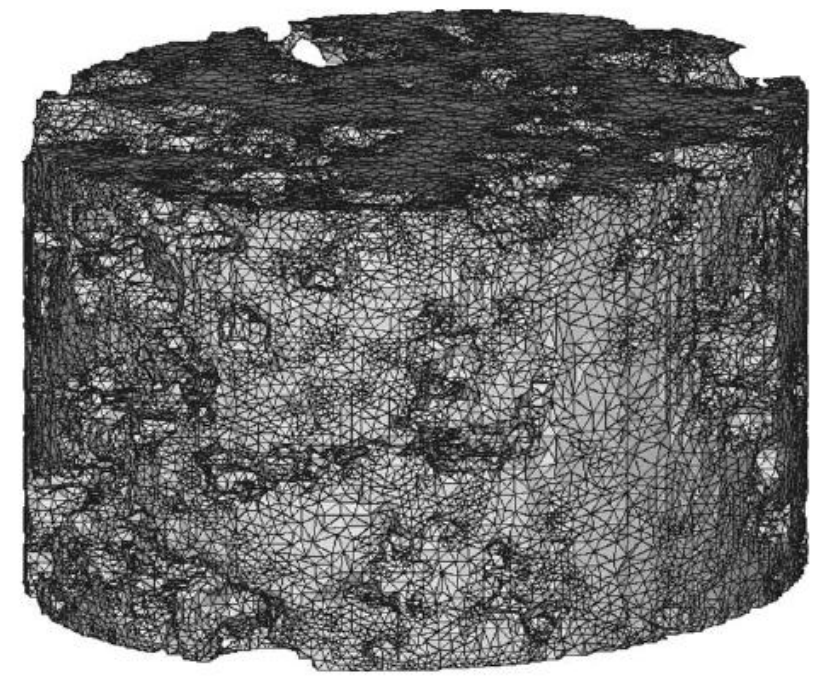

(c)

FIG. 12: Tetrahedral mesh of (a) a polyurethane foam ${ }^{7}$, (b) a nickel foam ${ }^{10}$ and (c) a porous $\beta$ tricalcium phosphate ${ }^{16}$ 


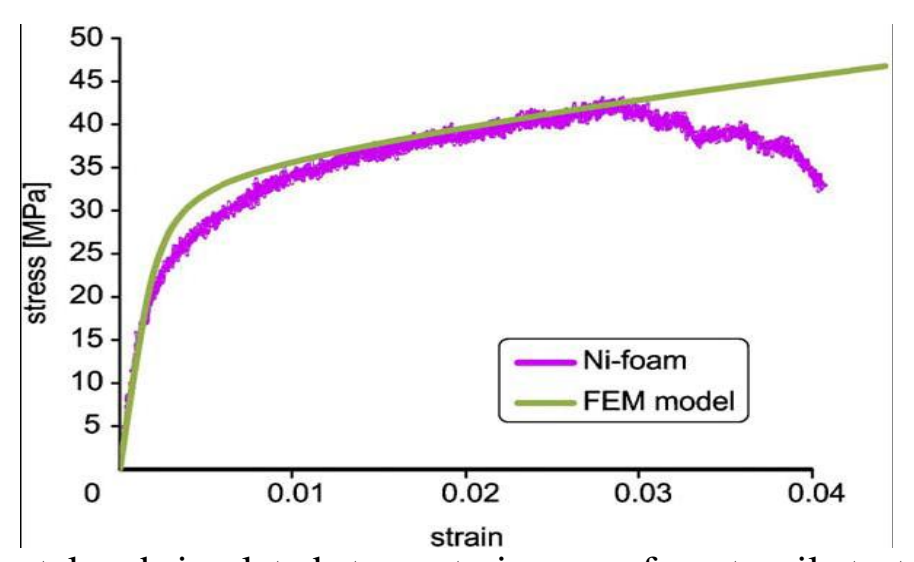

FIG. 13: Experimental and simulated stress strain curve for a tensile test of a nickel foam ${ }^{21}$

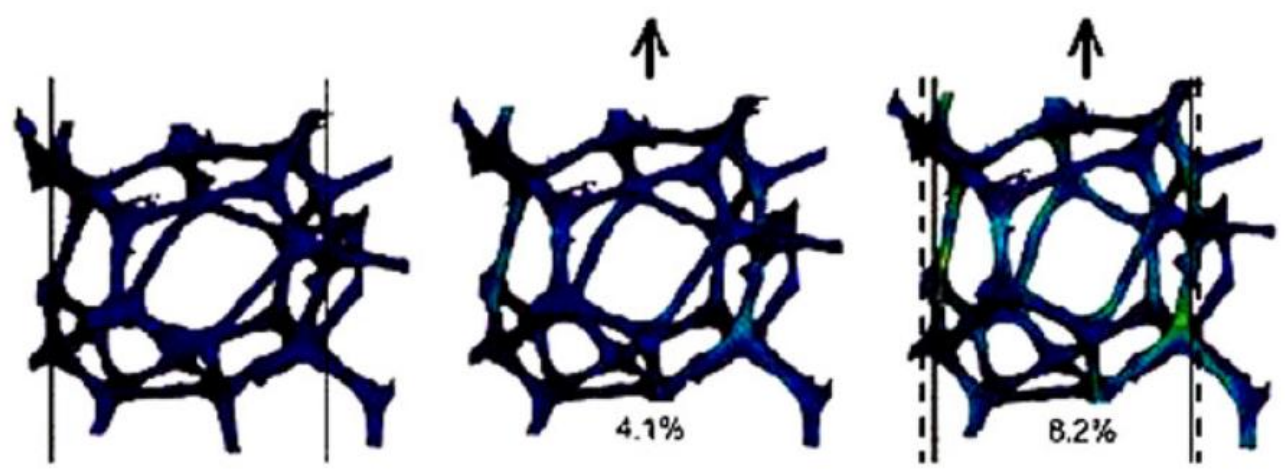

FIG. 14. FE modeling based on tomographic images. The images represent the stress contours for: (left) initial state, (middle) after a strain of $4.1 \%$, and (right) after a strain of $8.2 \%$

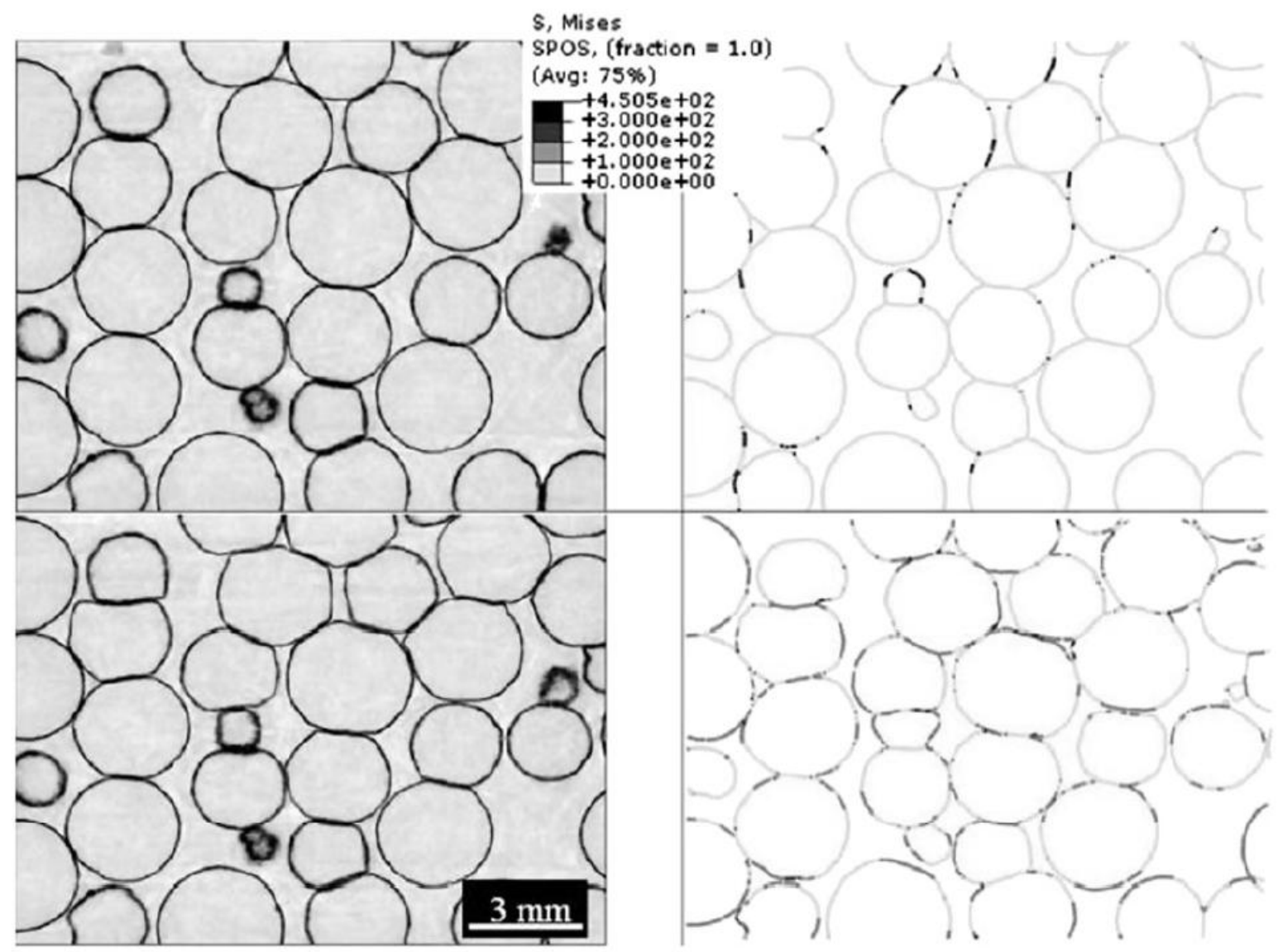

(a)

(b) 
FIG. 15. Comparison between (a) two tomographic slices of the stainless steel hollow sphere structure during a compression test and (b) the corresponding slices numerically simulated by

FE calculation. The upper figures correspond to a strain of $0.02 \%$ and the bottom figures correspond to a strain of $9 \% .24$ The explanations about the modeling conditions are given in Sec. III. B.

\section{d) Other types of meshing}

Other techniques are possible to mesh a cellular solid, such as mixed meshes made of different elements ${ }^{22}$. First, the solid surface is meshed with triangles. Then, a volume mesh is created with hexahedra. Tetrahedra and pentahedra are added where hexahedra cannot fill the overall volume. The comparison of different meshes for metallic foam shows that mixed meshes give the most accurate results. The discrete element method was also used to simulate the mechanical behavior of entangled materials (made of fibers) ${ }^{48}$. This technique consists of discretizing the fibers in segments. It then oversimplifies the description of the material but is useful when friction problems are pre- valent in the material to be analyzed, and the computation time can sometimes be reduced compared to the FE analysis.

\section{Conclusion}

X-ray tomography has become one of the preferred methods of characterization for studying cellular solids. The 3D images enable us to obtain a good description of the architecture of the foams. Applied at different scales, using either a standard mode of acquisition or local tomography, the technique permits a more precise de- scription of the material microstructure. XRCT images are often used to create meshes for FE modeling. Every class of cellular solids (polymer, ceramic, and metal) has been investigated using this combination of techniques. The subsequent FE calculations lead to results in terms of macroscopic properties that can be compared with standard mechanical tests. Many studies have reported that the prediction of this type of calculation is in good agreement with the macroscopic response of the material, although they seem to lead to a systematic overestimation of the elastic properties (Fig. 10). XRCT also allows us to follow the deformation processes of cellular solids when coupled with an in situ mechanical test. In this case, the FE prediction of the local stress concentration can also highlight the regions where stresses localize. This has been shown many times to be in good agreement with the local damage mechanism observed during in situ mechanical tests. This is illustrated by Fig. 15. This combination of techniques is then ready to be applied as a predictive tool. Either based on a tomographic image, or on a numerically generated microstructure, FE models can help engineers to select the best microstructure for a given property (then for a given application) without the need for a complex experimental investigation based on mechanical tests. This could be particularly useful in the case of multiaxial loading, which is not easy to carry out experimentally.

\section{References}

1. L.J. Gibson and M.F. Ashby: Cellular Solids: Structure and Properties, 2nd ed. (Cambridge University Press, Cambridge, England, 1997), p. 510.

2. E. Maire: X-ray tomography applied to the characterization of highly porous materials. Annu. Rev. Mater. Res. 42, 7.1 (2012).

3. J.Y. Buffière, E. Maire, J. Adrien, J.P. Masse, and E. Boller: In situ experiments with x ray tomography: An attractive tool for exper- imental mechanics. Exp. Mech. 50, 289 (2010). 
4. J. Baruchel, J.Y. Buffière, E. Maire, P. Merle, and G. Peix: X-Ray Tomography in Materials Science (Hermès Science Publications, Paris, France, 2000), p. 204.

5. S.R. Stock: Recent advances in x-ray microtomography applied to materials. Int. Mater. Rev. 53, 129 (2008).

6. F. Fischer, G.T. Lim, U.A. Handge, and V. Altstdt: Numerical simulations of mechanical properties of cellular materials using computing tomography analysis. J. Cell. Plast. 45, 441 (2009).

7. S. Youssef, E. Maire, and R. Gaertner: Finite element modeling of the actual structure of cellular material determined by X-ray tomography. Acta Mater. 53, 719 (2005).

8. P. Viot, D. Bernard, and E. Plougonven: Polymeric foam under dynamic loading by the use of the microtomographic technique. J. Mater. Sci. 42, 7202 (2007).

9. S. McDonald, G. Dedreuil-Monet, Y. Yao, A. Alderson, and

P. Withers: In situ 3D X-ray microtomography study comparing auxetic and non-auxetic polymeric foams under tension. Phys. Status Solidi B 45, 248 (2011).

10. A. Burteau, F. N'Guyen, J.D. Bartout, S. Forest, Y. Bienvenu,

S. Saberi, and D. Nauman: Impact of material processing and deformation on cell morphology and mechanical behavior of poly- urethane and nickel foams. Int. J. Solids Struct. 49, 2714 (2012).

11. E. Maire, P. Colombo, J. Adrien, L. Babout, and L. Biasetto: Characterisation of the morphology of cellular ceramics by 3D image processing of X-ray tomography. J. Eur. Ceram. Soc. 27, 1973 (2007).

12. J. Zeschky, F. Goetz-Neuhoeffer, J. Neubauer, S.H. Jason Lo,

B. Kummer, M. Scheffler, and P. Greil: Preceramic polymer derived cellular ceramics. Compos. Sci. Technol. 63, 2361 (2003).

13. S. Meille, M. Lombardi, J. Chevalier, and L. Montanaro: Mechanical properties of porous ceramics in compression: On the transition between elastic, brittle, and cellular behavior. $J$. Eur. Ceram. Soc. 32, 3959 (2012).

14. C. D'Angelo, A. Ortona, and P. Colombo: Finite elements analysis of reticulated ceramics under compression. Acta Mater. 60, 6692 (2012).

15. L. Zhang, J.M.F. Ferreira, S. Olhero, L. Courtois, E. Maire, T. Zhang, and J.C. Rauhe: Modeling the mechanical properties of optimally processed cordierite-mullite-alumina ceramic foams by X-ray computed tomography and finite element analysis. Acta Mater. 60, 4235 (2012).

16. D. Lacroix, A. Chateau, M.P. Ginebra, and J.A. Planell: Micro-finite element models of bone tissue-engineering scaffolds. Biomaterials 27, 5326 (2006).

17. C. Renghini, A. Giuliani, S. Mazzoni, F. Brun, E. Larsson, F. Baino, and C. VitaleBrovarone: Microstructural characterization and in vitro bioactivity of porous glass-ceramic scaffolds for bone regeneration by synchrotron radiation X-ray microtomography. J. Eur. Ceram. Soc. DOI: 10.1016/j.jeurceramsoc.2012.10.016.

18. Y. Okanoue, M. Ikeuchi, R. Takemasa, T. Tani, T. Matsumoto, M. Sakamoto, and M. Nakasu: Comparison of in vivo bioactivity and compressive strength of a novel superporous hydroxyapatite with beta-tricalcium phosphate. Arch. Orthop. Trauma Surg. 132, 1603 (2012).

19. G. Gioux, T.M. McCormack, and L.J. Gibson: Failure of aluminum foams under multiaxial loads. Inter. J. Mech. Sci. 42, 1097 (2000).

20. I. Jeon, T. Asahina, K.J. Kang, S. Im, and T.J. Lu: Finite element simulation of the plastic collapse of closed-cell aluminum foams with X-ray computed tomography. Mech. Mater. 42, 227 (2010).

21. N. Michailidis, F. Stergioudi, H. Omar, D. Papadopoulos, and D.N. Tsipas: Experimental and FEM analysis of the material response of porous metals imposed to mechanical loading. 
Colloids Surf., A 382, 124 (2011).

22. C. Veyhl, I.V. Belova, G.E. Murch, A. Oschner, and T. Fiedler: On the mesh dependence of non-linear mechanical finite element analysis. Finite Elem. Anal. Des. 46, 371 (2010).

23. T. Guillén, Q.H. Zhang, G. Tozzi, A. Orhndorf, H.J. Christ, and

J. Tong: Compressive behavior of bovine cancellous bone and bone analogous materials, microCT characterisation and FE analysis. J. Mech. Behav. Biomed. Mater. 4, 1452 (2011).

24. O. Caty, E. Maire, S. Youssef, and R. Bouchet: Modeling the properties of closed-cell cellular materials from tomography images using finite shell elements. Acta Mater. 56, 5524 (2008).

25. P. Lhuissier, L. Salvo, and Y. Bréchet: Quasistatic mechanical behavior of stainless steel hollow sphere foam: Macroscopic properties and damage mechanisms followed by X-ray tomogra- phy. Mater. Lett. 63, 1113 (2009).

26. R. Singh, P.D. Lee, T.C. Lindley, C. Kohlhauser, C. Hellmich, M. Bram, T. Imwinkelried, and R.J. Dashwood: Characterization of the deformation behavior of intermediate porosity interconnected $\mathrm{Ti}$ foams using micro-computed tomography and direct finite element modeling. Acta Biomater. 6, 2342 (2010).

27. M. Saadatfar, F. Garcia-Moreno, S. Hutzler, A.P. Sheppard, M.A. Knackestedt, J. Banhart, and D. Weaire: Imaging of metallic foams using X-ray micro-CT. Colloids Surf., A 344, 107 (2009).

28. S. Van Bael, G. Kerckhofs, M. Moesen, G. Pyka, J. Schrooten, and J.P. Kruth: Micro-CTbased improvement of geometrical and mechanical controllability of selective laser melted Ti6Al4V porous structures. Mater. Sci. Eng., A 528, 7423 (2011).

29. F. Tariq, R. Haswell, P.D. Lee, and D.W. McComb: Characteriza- tion of hierarchical pore structures in ceramics using multiscale tomography. Acta Mater. 59, 2109 (2011).

30. IMorph: IMorph [online]. Available on: , www.imorph.com ..

31. L. Brabant, J. Vlassenbroeck, Y. De Witte, V. Cnudde,

M.N. Boone, J. Dewanckele, and L. Van Hoorebeke: Three- dimensional analysis of highresolution X-ray computed tomogra- phy data with Morpho1. Microsc. Microanal. 17, 252 (2011).

32. H. Toda, T. Kobayashi, M. Niimoni, T. Ohgaki, M. Kobayashi, M. Kuroda, T. Akahori, K. Uesugi, K. Makii, and Y. Aruga: Quantitative assessment of microstructure and its effect on compressive behavior of aluminum foams via high resolution synchrotron X-ray tomography. Metall. Mater. Trans. A 37, 1211 (2006).

33. J.L. Grenestedt and K. Tanaka: Influence of cell shape variations on elastic stiffness of closed cell cellular solids. Scr. Mater. 40, 71 (1999).

34. N.A. Fleck, O.B. Olurin, C. Chen, and M.F. Ashby: The effect of hole size upon the strength of metallic and polymeric foams. J. Mech. Phys. Solids 49, 2015 (2001).

35. E. Maire, A. Fazekas, L. Salvo, R. Dendievel, S. Youssef, P. Cloetens, and J.M. Létang: $\mathrm{X}$-ray tomography applied to the characterization of cellular materials. Related finite element mod- eling problems. Compos. Sci. Technol. 63, 2431 (2003).

36. C. Berre, S.L. Fok, P.M. Mummery, J. Ali, B.J. Marsden, T.J. Marrow, and G.B. Neighbour: Failure analysis of the effects of porosity in thermally oxidised nuclear graphite using finite element modeling. J. Nucl. Mater. 381, 1 (2008).

37. M. Saadatfar, C.H. Arns, M.A. Knackstedt, and T. Senden: Mechan- ical and transport properties of polymeric foams derived from 3D images. Colloids Surf. A 263, 284 (2005).

38. E.J. Garboczi and A.R. Day: An algorithm for computing the effective linear elastic properties of heterogeneous materials: Three- dimensional results for composites with equal phase poisson ratios. J. Mech. Phys. Solids 43, 349 (1995).

39. C.H. Arns, M.A. Knackstedt, W. Val Pinczewski, and E.J. Garboczi: Computation of linear elastic properties from micro- tomographic images: Methodology and agreement between 
theory and experiment. Geophysics 67, 1396 (2002).

40. T. Fiedler, S.M.H. Hosseini, I.V. Belova, G.E. Murch, and

A. Ochsner: A refined finite element analysis on the thermal conductivity of perforated hollow sphere structures. Comp. Mater. Sci. 47, 314 (2009).

41. A.P. Roberts and E.J. Garboczi: Elastic moduli of model random three-dimensional closedcell cellular solids. Acta Mater. 49, 189 (2001).

42. J. Escoda, F. Willot, D. Jeulin, J. Sanahuja, and C. Toulemonde: Estimation of local stresses and elastic properties of a mortar sample by FFT computation of fields on a 3D image. Cem. Concr. Res. 41, 542 (2011).

43. J.A. Elliott, A.H. Windle, J.R. Hobdell, G. Eeckhaut, R.J. Oldman,

W. Ludwig, E. Boller, P. Cloetens, and J. Baruchel: In-situ deformation of an open-cell flexible polyurethane foam character- ized by 3D computed tomography. J. Mater. Sci. 37, 1547 (2002).

44. D. Ulrich, B. Van Rietbergen, H. Weinans, and P. Rüegsegger: Finite element analysis of trabecular bone structure: A comparison of image-based meshing techniques. J. Biomech. 31, 1187 (1998).

45. M. Vesenjak, C. Veyhl, and T. Fiedler: Analysis of anisotropy and strain rate sensitivity of open-cell metal foam. Mater. Sci. Eng., A 541, 105 (2012).

46. V. Marcadon, C. Davoine, B. Passilly, D. Boivin, F. Popoff,

A. Rafray, and S. Kruch: Mechanical behavior of hollow-tube stackings: Experimental characterization and modeling of the role of their constitutive material behavior. Acta Mater. 60, 5626, (2012).

47. C. Sandino, J.A. Planell, and D. Lacroix: A finite element study of mechanical stimuli in scaffolds for bone tissue engineering. J. Biomech. 41, 1005 (2008).

48. C. Barbier, R. Dendievel, and D. Rodney: Numerical study of 3D- compressions of entangled materials. Comp. Mater. Sci. 45, 593 (2009). 